\title{
1. Neurodisability and the criminal justice system: a problem in search of a solution
}

\author{
Gaye T. Lansdell, Bernadette Saunders, Anna \\ Eriksson
}

People with neurodisability are over-represented in criminal justice populations around the world. However, despite a growing number of international studies confirming the high prevalence rates of mental illness, intellectual, cognitive and developmental disorders in custodial settings, ${ }^{1}$ less attention has been paid to the critical elements of the justice systems that perpetuate often unnecessary and undesirable criminal justice intervention in these people's lives. Broadly, neurodisability includes acquired brain injury (ABI) and/or traumatic brain injury (TBI), autism, fetal alcohol spectrum disorder (FASD), and intellectual disability, all of which are the focus of this book. Research, exposing the negative impacts of criminal justice processes on people living with neurodisabilities, has identified multiple factors that heighten the likelihood of imprisonment, and draws attention to symptomatic behaviours that are

1 Eric J. Shiroma, Pamela Ferguson and Elizabeth Pickelsimer, 'Prevalence of Traumatic Brain Injury in an Offender Population: A Meta-analysis' (2010) 16(2) The Journal of Head Trauma Rehabilitation 147 (a meta-analysis of TBI prevalence for adults imprisoned for violent crime in the United States, the United Kingdom, New Zealand and Australia); Glenn Kelly, Suzanne Brown, Grahame K. Simpson 'The Building Bridges Project: Linking Disconnected Service Networks in Acquired Brain Injury and Criminal Justice' (2020) 30(3) Neuropsychological Rehabilitation 481 (ABI in prisons in Australia); Clare Allely, 'Prevalence and Assessment of Traumatic Brain Injury in Prison Inmates: A Systematic PRISMA Review' (2016) 30(10) Brain Injury 1161 (UK prisons); Ruth McCausland, Eileen Baldry, Sarah Johnson, Anna Cohen, 'People with Mental Health Disorders and Cognitive Impairment in the Criminal Justice System: Cost Benefit Analysis of Early Support and Diversion' University of New South Wales (2013) https://humanrights.gov.au/sites/default/files/document/ publication/Cost $\% 20$ benefit\%20analysis.pdf [accessed 29 November 2020] (extensive focus on the scale of neurodisablities generally in prison populations in New South Wales, Australia). 
commonly criminalised, often leading to further entanglement in the system. ${ }^{2}$ Even with this growing multidisciplinary awareness, few jurisdictions have adequately focused on how criminal justice systems can better accommodate this often vulnerable group's needs and, in turn, reduce the risk of justice system exposure and engagement.

This book brings together a diverse group of international scholars and practitioners from Australia, the United Kingdom and the United States. The chapters highlight the extent and complexity of the issue of over-engagement of people with a neurodisability in justice systems around the world, and present practical solutions to address this concerning issue. By the integration of previously separate research findings, this book makes a significant contribution to the field of neurodisability research and sheds light on the prevalence of multiple disabilities in justice systems. The book's authors discuss the specific needs of different groups of people with neurodisability, as well as the multiple and diverse challenges they face. Most importantly, the book is solutions-focused, recommending what needs to change in the justice system to better accommodate both the general and the specific needs of people with neurodisabilities.

\section{THE SCALE OF NEURODISABILITY FOR COURT SYSTEMS}

Use of the umbrella term 'neurodisability' prompts the need to explore the various disabilities and co-morbid conditions that sit under this umbrella, and to discover and address the differing, often questionable, reactions and responses that persons living with these conditions experience. For example,

2 Nathan Hughes, Huw Williams, Prithaba Chitsabesan, Rebecca Davies and Luke Mounce (2012) Nobody made the connection: the prevalence of neurodisability in young people who offend. London: Office of the Children's Commissioner. See www.childrenscommissioner.gov.uk/wp-content/uploads/2017/07/Nobody-made-the -connection.pdf [accessed 12 March 2020]; Gaye T. Lansdell, Bernadette Saunders, Anna Eriksson, Rebecca Bunn and Susan Baidawi, 'Enhancing the Rights and Well-being of People with Acquired Brain Injuries in the Criminal Justice System: Some Findings from a Qualitative Study' (2018a) 53(2) Australian Journal of Social Issues 88; Gaye T. Lansdell, Bernadette Saunders, Anna Eriksson, Rebecca Bunn, Susan Baidawi, "I am not drunk, I have an ABI": Findings From a Qualitative Study into Systematic Challenges in Responding to People with Acquired Brain Injuries in the Criminal Justice System' (2018b) 25(5) Psychiatry, Psychology and Law 737; Anna Eriksson, Bernadette Saunders, Gaye T. Lansdell, Rebecca Bunn 'Short Fuse and no Filter: Acquired Brain Injury - How a Medical Disability Transforms into a Social and Criminal Justice Concern' (2019) 57 International Journal of Law, Crime and Justice 126. 
people living with an ABI or TBI have been found to encounter significant difficulties in navigating criminal justice systems. ${ }^{3}$ Moreover, the research of Hughes et al. ${ }^{4}$ has uncovered significant overrepresentation of people with neurodisability within juvenile justice populations in the United Kingdom. This includes rates of between 60 and 90 per cent for communication disorders, between 23 and 32 per cent for intellectual disabilities, and significantly higher rates of reported head injury. A number of meta-analyses have shown the high prevalence of TBI/ABI amongst prisoners, ${ }^{5}$ with one of the most recent studies estimating that an average of 45 per cent of prisoners have an ABI. ${ }^{6}$

People with intellectual disability (ID) are likewise considered to be over-represented in adult prison populations, although prevalence rates remain unclear. ${ }^{7}$ Poor methodological rigour in research, differing definitions of ID and varying approaches to assessment, render comparison between studies complex, and results vary considerably. ${ }^{8}$ Nevertheless, a recent systematic

3 Hughes et al. (n. 2); Lansdell et al. 2018(a) (n. 2); Lansdell et al. 2018(b) (n. 2); Eriksson et al. (n. 2).

4 Nathan Hughes, Huw Williams, Prathiba Chitsabesan, Rebecca Walesby, Luke Mounce and Betony Clasby, 'The Prevalence of Traumatic Brain Injury Among Young Offenders in Custody: A Systematic Review' (2015) 3(2) Journal of Head Trauma Rehabilitation 94-105.

5 Shiroma et al. (n. 1); Thomas Farrer and Dawson Hedges, 'Prevalence of Traumatic Brain Injury in Incarcerated Groups Compared to the General Population: A Meta-analysis' (2011) 35 Progress in Neuro-Psychopharmacology \& Biological Psychiatry 390-94; Rebecca Davies, Huw Williams, Darren Hinder, Crispin Burgess and Luke Mounce 'Self-reported Traumatic Brain Injury and Post-concussion Symptoms in Incarcerated Youth' (2012) 27(3) Journal of Head Trauma Rehabilitation 801; Hughes, et al. (2015) ibid.; Allely (n. 1); Eric Durand, Matilde Chevignard, Alex Ruet, A. Dereix, Christel Jourdan and Pascale Pradat-Diehl, 'History of Traumatic Brain Injury in Prison Populations: A Systematic Review' (2017) 60 Annals of Physical and Rehabilitation Medicine 95.

6 Durand, ibid.

7 Julian Trollor and Simone Reppermund, Response to the Senate inquiry into indefinite detention of people with cognitive and psychiatric impairment in Australia. Submission to the Senate Standing Committees on Community Affairs (Department of Developmental Disability Neuropsychiatry, UNSW 2016); A. Bhandari, Kate Van Dooren, G. Eastgate, Nicholas Lennox, Stuart Kinner (2015). 'Comparison of Social Circumstances, Substance Use and Substance-related Harm in Soon-to-be-Released Prisoners with and Without Intellectual Disability' (2015) 59(6) Journal of Intellectual Disability Research 571; McCausland et al. (2013) (n. 1).

8 Margaret Nixon, Stuart Thomas, Michael Daffern and James Ogloff, 'Estimating the Risk of Crime and Victimisation in People with Intellectual Disability: A Data-linkage Study' (2017) 52 Social Psychiatry and Psychiatric Epidemiology 617; Shasta Holland and Peter Persson, 'Intellectual Disability in the Victorian Prison System: Characteristics of Prisoners with an Intellectual Disability Released from Prison in 2003-2006' (2011) 17(1) Psychology, Crime \& Law 25. 
review suggested that the prevalence of ID amongst prison populations is between 7 and 10 per cent ${ }^{9}$ with the rate of borderline ID amongst prisoners being closer to 30 per cent. ${ }^{10}$ In a similar vein, there is increasing community concern about the difficulties that people with fetal alcohol spectrum disorder (FASD) and other developmental disorders face, particularly when they come into contact with criminal justice systems. ${ }^{11}$ While rigorous empirical studies remain limited, early global indications suggest that people with FASD are at a disproportionately higher risk than the general community in becoming involved in the criminal justice system and may, at all age levels, be over-represented amongst prisoner populations. ${ }^{12}$

9 Mike Hellenback, Thanos Karatzias and Michael Brown, 'Intellectual Disabilities Among Prisoners: Prevalence and Mental and Physical Health Comorbidities' (2017) 30 Journal of Applied Research in Intellectual Disabilities 230.

10 Hellenback ibid.; Susan Hayes, Phil Shackell, Pat Mottram and Rachel Lancaster 'The Prevalence of Intellectual Disability in a Major UK Prison' (2007) 35 British Journal of Learning Disabilities, 162; Eileen Baldry, Melissa Clarence, Leanne Dowse, Julian Trollor, 'Reducing Vulnerability to Harm in Adults with Cognitive Disabilities in the Australian Criminal Justice System' (2013) 10(3) Journal of Policy and Practice in Intellectual Disabilities 222.

${ }_{11}$ Katherine Wyper and Jacqueline Pei, 'Neurocognitive Difficulties underlying High Risk and Criminal Behaviour in FASD: Clinical Implications' in M. Nelson and M. Trussler (eds.) Fetal Alcohol Spectrum Disorders in Adults: Ethical and Legal Perspectives (Springer International Publishing, 2016); Elizabeth Moore, Sandra Sunjic, Sharlene Kaye, Vicki Archer, Devon Indigo, 'Adult ADHD Among NSW Prisoners: Prevalence and Psychiatric Comorbidity' (2016) 20(11) Journal of Attention Disorders 958; Nathan Hughes, Betony Clasby, Prathiba Chitsabesan, Huw Williams, 'A Systematic Review of the Prevalence of Foetal Alcohol Spectrum Disorders Among Young People in the Criminal Justice System' (2016) 3(1) Cogent Psychology 1214213.

12 Svetlana Popova, Shannon Lange, Dennis Bekmuradov, Alanna Mihic and Jürgen Rehm, 'Fetal Alcohol Spectrum Disorder Prevalence Estimates in Correctional Systems: A Systematic Literature Review' (2011) 102 Canadian Journal of Public Health 336; Patricia MacPherson, Albert Chudley and B. A. Grant, Fetal alcohol spectrum disorder (FASD) in a correctional population: Prevalence, screening and characteristics (Correctional Service of Canada 2011); Katherine Flannigan, Jacqueline Pei, Michelle Stewart Alexandra Johnson, 'Fetal Alcohol Spectrum Disorder and the Criminal Justice System: A Systematic Literature Review'(2018) 57 Internal Journal of Law and Psychiatry 42; Dianne K. Fast and Julianne Conry, 'Fetal Alcohol Spectrum Disorders and the Criminal Justice System' (2009) 15 Developmental Disabilities Research Reviews 250. 


\section{THE PROJECT THAT FORMED THE BASIS FOR THE BOOK}

Research that we conducted in Victoria, Australia, sparked the idea to initiate and edit this book. Our research (Lansdell et al.) began with the intent of better understanding the incidence of, and responses to, ABI within criminal justice populations in that state. Over seven years we engaged in extensive qualitative research involving key stakeholders, including judicial officers, police prosecutors, various service providers, legal personnel and also persons living with an $\mathrm{ABI}$ who had prior contact with the criminal justice system.

After interviewing over 102 stakeholders over an 18-month period, the findings from that project were substantial and have been reported elsewhere. ${ }^{13}$ The key issues were:

- misunderstandings generally about ABI, how to manage it and how to foster inclusivity;

- the existence of multiple layers of disadvantage or co-morbidity that render persons with $\mathrm{ABI}$ vulnerable to contact with the criminal justice system;

- inadequate systemic responses - such as lack of suitable accommodation and lack of community support - create pathways to offending for ABI persons;

- lack of early identification of people with ABI in the criminal justice process creates missed opportunities for diversion, treatment and support;

- there is a need for greater use of neuropsychological testing funded by the government and even earlier identification in childhood;

- lack of awareness and education among legal professionals as to ABI signs and sequelae prompts the need for compulsory training for all legal and justice practitioners including police, lawyers, judiciary and prison officers. This also reinforces the necessity of inter-agency and inter-professional cooperation;

- lack of understanding of the impact of ABI on compliance with court appearances and sentencing orders, which creates barriers to effective engagement in legal processes. For these reasons, consideration should be given to other therapeutic models including expanding court support programmes;

13 Bernadette Saunders, Gaye T. Lansdell, Anna Eriksson, Rebecca Bunn, 'Friend or Foe: the Media's Power to Inform and Shape Societal Attitudes Towards People with Acquired Brain Injury' (2018) 33(6) Disability \& Society 932; Lansdell et al. (2018a) (n. 2); Lansdell et al. (2018b) (n. 2); Eriksson et al. (n. 2). 
- the absence of specialised units and ABI clinicians for people with $\mathrm{ABI}$ in prisons, and a corresponding lack of support upon release, which perpetuates the involvement of people with an $\mathrm{ABI}$ in the justice system.

During that research project, we were introduced to, and networked with, many of the authors that we selected for this volume. Given their professional specialities either in Australia or globally, they were each working with and/ or researching a range of cognitive conditions and the interplay between these and the criminal justice systems in their respective jurisdictions. In early 2019, the Australian Institute of Criminology funded us to further our initial research but with a focus on youth offenders. That research is ongoing. It is notable, however, that a number of this book's authors, particularly from the United Kingdom, specialise in the area of youth justice and their chapters focus on important and innovative developments in that area in that country. The issues that they raise and discuss, in their individual chapters, mirror the findings we have now tentatively uncovered in Australia.

We were fortunate, in 2019, to organise a meeting for some of the authors, at the Monash campus in Prato Tuscany providing them with a rare opportunity for reflection, discussion and debate. The meeting also enabled comment on various contributions to this book, and the refinement of key themes and recommendations for future best practice. These are outlined in this introduction and the book's concluding chapter. For us, this was a culmination of many years' work in the area of neurodisability stemming from a number of successful competitive grants. This work built on our individual areas of academic interest and expertise - a legal scholar with professional and academic expertise in criminal law, a human rights academic, with social work qualifications, and an extensive publication record, particularly in the area of children's rights, and a criminologist with special expertise in penology - a truly interdisciplinary endeavour. Decisions were made as to how to include important global issues such as capacity, screening, systemic risk and harm, gender issues, social policy, public health approaches and human and positive rights approaches, particularly the US right to due process and other international covenants advancing the rights of persons with disabilities. The participants found the meeting inspiring and challenging but re-energising. In this sense, the writing of these chapters did not take place in a vacuum, but instead genuine debate has occurred of the key ideas. Most authors had written drafts of their chapters before they met together. Authors then provided final versions based on feedback received and other considerations.

The resulting collection of essays is divided into three main parts. The first, which provides the context for the book, is titled Understanding and Responding to Neurodisability. The second part focuses on, and is titled, the Needs of Young People with Neurodisability. The third and final part, titled 
Responses to Neurodisability within the Criminal Justice System, considers the challenges that justice systems face when developing responses which recognise, and are sensitive to, the nature and impact on people of the various forms of neurodisability and associated co-morbidities.

\section{INTRODUCING THE CHAPTERS}

While this book predominantly focuses on the interaction of neurodisability with justice systems, some chapters also consider specific community contexts that interact with justice systems, in order to demonstrate how some of the difficulties associated with neurodisability are created and reinforced across different spaces. Such an approach recognises that the justice system is interdependent on community organisations which come into contact with people with neurodisability. Each chapter describes and discusses best practices occurring in communities that constructively address the issues and needs of people living with a neurodisability, to shed light on ways in which justice systems could more appropriately engage and respond, when necessary. The combined chapters set out systematic and coordinated ways forward that are tailored to the diverse needs of this vulnerable cohort.

The first part of the book opens with Professor Amanda Pustilnik's chapter. Amanda is a US legal scholar who explores the concept of neurodisability as a definition of a human condition and behaviour that does not fall within the generally accepted realms of insanity. Her chapter titled 'Neurodisability: A Criminal Law Doctrine that is not Pure Insanity' sets the scene with a description of a system that is deficient in that it only considers either an insane or a sane mind from which criminal processes and procedures flow. This system largely ignores conditions that fall between the two realms, in terms of both legal responsibility and sentencing provisions. This imperfect system is highly challenged when faced with emerging neurodisabilities.

We then move to Dr Joseph Wszalek's contribution. He further highlights the system's inadequacies, particularly regarding legal systems and language. His chapter, 'A Public Law Model for Cognitive-Communication Risk', illustrates how typically technical legal language excludes and potentially perpetuates injustice for individuals with language and cognitive-communication limitations. The adversarial system (common to the legal systems of the United States, the United Kingdom and Australia) relies on cognitive communication in all its processes, but this becomes more acute in the criminal trial process. Later chapters (9-11) pertaining to communication issues within the criminal process also confirm that the system places a great burden on its lawyers, in the first instance, to resolve barriers to communication on behalf of their clients. Dr Wszalek's main thesis is that cognitive limitations, and the criminal offending that ensues from those conditions, should be recharacterised as public 
law/ public-health matters in order to address systemic challenges for these offenders. Where the criminal justice system with its own structural limitations and lack of resourcing, has traditionally floundered, a public health or public law framework and approach would stimulate the provision of much-needed supports and services for people with cognitive disabilities.

Situating the book in the context of international guidelines and covenants relating to persons living with disabilities, Professor Penelope Weller contributed Chapter 4. Australia's ratification of both the United Nations Convention on the Rights of Persons with Disabilities and the Optional Protocol Against Torture and Other Inhuman or Degrading Treatment and Punishment has created a strong imperative to respond appropriately to those with neurodisabilities or acquired brain injuries. Surprisingly, however, there appears to be little discussion about the implications of these international treaties for criminal justice system reform in Australia. This chapter sketches out the obligations contained in these two human rights treaties in the context of the criminal justice system and offers a framework and agenda for future reform. The conclusions gleaned from this chapter bear global relevance for all jurisdictions that have ratified the covenants.

The second part of the book specifically focuses on young persons with neurodisabililties, and this part begins in the United Kingdom where there has been substantial activity since 2010 on raising awareness of issues around neurodisability in the criminal justice system in relation to young offenders. Chapter 5 is titled: 'Dismantling Barriers to Justice for Children Affected by Neurodisability'. In this essay, Frances Sheahan and Professors Nathan Hughes, Huw Williams and Prathiba Chitsabesan examine the need to revisit the institutional cultures within youth justice systems that are based on trauma-informed practices, and instead provide a culture of support that prioritises rehabilitation rather than punishment. In tandem with Professor Weller, this chapter demonstrates how youth justice systems (from police interview to court appearance to community intervention to experiences of custody) are at odds with international covenants on the rights of all young people, and especially those with disabilities, and it posits therapeutic justice as an alternative framework for intervention.

Continuing in the area of youth justice, Professor Huw Williams, Dr Leigh Schrieff, Professors Nathan Hughes, James Tonks, Prathiba Chitsabesan and Dr Hope Kent contribute Chapter 6, 'Neurodisability and Trauma in Children and Young People in Contact with the Law'. In this chapter, they consider the importance of systematic screening and assessment for cognitive disabilities at various stages of the criminal justice processes and procedures, with particular reference to young people within or at risk of incarceration. The authors present cases to illustrate how, in both the community and secure justice settings, TBI can be managed to enable improved rehabilitation. They advocate for earlier, 
more targeted, preventative work within better systems to reduce the chances and effects of injury, and increasing community interventions to manage neurodisability reactions that invoke punitive justice system responses.

Shauneen Lambe and Professor Kathryn Hollingsworth in their chapter, 'Protecting Vulnerable Child Defendants in England and Wales: A House of Cards?', narrow the focus further to pure legal case studies of young persons with neurodisabilities facing court processes in England and Wales. Their particular consideration is an analysis of the associated decline in granting rights to children with neurodisabilities. Following the European Court of Human Rights decision in $V v$ United Kingdom ((1999) 30 EHRR 121), these authors acknowledge and discuss the associated peril for young persons that this case has resulted in. They present a convincing argument that increasingly punitive models applied to young offenders in the past decade in that jurisdiction have brought many young persons into the domain of the criminal justice system, including those living with neurodisabilities. To rewind this cycle, they recommend introducing statutory protections to safeguard these vulnerable young persons.

In Chapter 8, Dr Hayley Passmore and Dr Sharynne Hamilton introduce the emerging impact of FASD, particularly in Australia. They highlight the impact of FASD on young persons who, not uncommonly progress through the criminal justice system. While governments have begun to recognise and address the effects of FASD, more professional awareness and training, and the development of appropriate responses, is necessary. Suggestions are made for improving the communication with young people so as to ensure that they are able to participate in the justice system in a fair and consistent manner, notwithstanding the impact of FASD on their neurodevelopment. The authors particularly highlight the challenges that young persons with FASD face throughout all stages of the justice system, drawing also on examples from North America for guidance and direction.

The third part of the book progresses to a more detailed analysis of the various areas of the criminal justice system. The main focus here is on the processes of court administration and the pathways through the system for a person with a neurodisability. The final three chapters in this part focus on the lived experience of people with neurodisabilities as they journey from the inception of legal assistance and first contact with legal practitioners, through to their court appearance, experience of judicial determinations, sentencing processes and, finally, correctional dispositions. People with neurodisabilities have been found to encounter difficulties in comprehending and navigating complex police, court and custodial processes, being unable to comply with sentencing orders that fail to accommodate their needs, and struggling with the transition from custody to the community in the absence of appropriate community-based support. A growing evidence base in relation to all types 
of neurodisability, suggests that the justice system is largely ill-equipped to respond effectively to their needs. These three chapters confirm and reinforce these findings, while making recommendations for future best practice.

In Chapter 9, we (Lansdell, Saunders, Eriksson and also Rebecca Bunn), examine the early stages of legal representation in the criminal process. Our chapter primarily focuses on lawyers, and confirms that neurodisability presents itself in complex ways, requiring personalised and specialised responses across the criminal justice system. The case is made that lawyers, in general, are inadequately trained to deal with medical matters, let alone evidence of neurodisabilities. However, legal scholarship reveals that many accused persons within the criminal justice system that come before the courts in Australia are living with a range of mental health conditions which may be directly relevant to the commission of the crime for which they are being prosecuted. It is likely that this same concern exists globally both as to legal training deficits and the numbers of persons within the criminal justice system living with a mental health issue or recognised disability. As suggested by the chapter's title, 'What do Lawyers Really Know about Neurodisability - Confusion, Obfuscation and Dereliction of Duty', we primarily consider the lawyers' roles and responsibilities in a system which structurally disadvantages persons living with such disabilities. While ABI is the particular focus of this chapter, given that it draws from the research project underlying this book, it reveals that the same issues befall other areas of neurodisability.

Continuing the same theme, and illustrating similar concerns, Chapter 10 presents Magistrate Pauline Spencer's judicial perspective on these matters. With her judicial expertise in a busy city court in Australia, she considers how changes could be made to current court systems to shift them towards 'agencies of dignity'. In her chapter, 'Towards Dignity: Better Court Pathways for People with Lived Experience of Acquired Brain Injury', she grapples with the ongoing experience of persons living with $\mathrm{ABI}$ appearing in courts. Magistrate Spencer explores how a therapeutic jurisprudence approach can be used to translate the current scientific knowledge into more effective criminal justice responses for people with ABI. Such responses include improvements to judicial court resolutions, and more effective application of options under bail and sentencing law.

Finally, Chapter 11 endeavours to connect practices inside and outside of prisons. Titled 'Neurodisability and the 'Revolving' Prison Door: An International Problem Viewed through an Australian Lens'. In this chapter, the editors consider the daily realities of prisoners living with an $\mathrm{ABI}$ and the challenges that they face both within the prison environment, and upon release, due to the fact that the justice system is a long way from adequately meeting their specific needs. The views of stakeholders who participated in the original research project in Victoria are collated and considered in this chapter, in 
conjunction with international scholarship. The dearth of accessible support in the community is highlighted, along with its associated effect on the inevitable cycle of recidivism for people living with neurodisabilities when their conditions cannot be treated or supported adequately. This chapter provides lessons for correctional governors and policy makers globally.

The book concludes with a summation of themes drawn both from the chapters and those debated when many of the authors met in Prato. As considered throughout, ABI, TBI, FASD and ID and other forms of disability are becoming increasingly recognised as major contributors to criminal behaviour, which pose significant challenges to the criminal justice system, particularly in developing responses which recognise and are sensitive to these disabilities. The conclusion, drawing on collective expertise from the disciplines of law, social work, criminology, psychology, neuropsychology and psychiatry, identifies future best practices across a range of contexts to assist the practice of law, social work and correctional rehabilitation to assist those who work within those realms. It is our hope that this book will provide an impetus for debate among wider audiences and lead those charged with the responsibility for improving the systems that perpetuate injustice, over-representation and recidivism towards urgent, constructive and humane action. 